\title{
A inserção profissional de professores de educação física iniciantes: aprendendo a ser professor
}

\author{
The employability of education beginners physics teachers: learning to be a teacher
}

\author{
La inserción laboral de los profesores de educación física principiantes: \\ aprender a ser un maestro
}

\author{
JosÉ ANGELO GARIGLIO*
}

\begin{abstract}
$\longrightarrow \nLeftarrow$
RESUMO

Este artigo relata os achados de uma pesquisa que trata dos aspectos singulares dos processos de iniciação à docência e à aprendizagem docente vivida por professores de educação física licenciados, egressos de uma universidade da rede federal de ensino. A metodologia de pesquisa é de cunho qualitativo, de caráter descritivo. $\mathrm{O}$ estudo foi realizado com 13 professores iniciantes (nove homens e quatro mulheres) e fez uso de duas técnicas de coleta de dados: entrevista e análises de casos de ensino. Os dados da pesquisa mostram que o pertencimento a um determinado campo disciplinar é um elemento importante a considerar para análise dos processos de inserção profissional e aprendizagem docente, já que definem modos particulares e cruciais de ser professor e de se inserir na profissão.
\end{abstract}

Palavras-chave: Formação de professores. Iniciação à docência. Aprendizagem docente. Educação física.

\begin{abstract}
This paper reports the findings of a survey that addresses the unique aspects of the initiation processes teaching and teacher learning experienced by teachers of physical education graduates, graduates of a university of the federal schools. The research methodology is qualitative nature, descriptive character. The study was conducted with 13 beginning teachers ( 9 men and 4 women) and made use of two data collection techniques: interview and analysis of teaching cases. The survey data show that membership in a particular subject area is an important element to consider for the analysis of profesional integration processes and teacher learning as they set specific and crucial ways to become a teacher and to enter the profession.
\end{abstract}

Keywords: Teacher training. Introduction to teaching. Teacher learning. Physical education.

\section{RESUMEN}

Este artículo presenta los resultados de una encuesta que se ocupa de los aspectos únicos de la iniciación de los procesos de enseñanza y aprendizaje docente experimentado por los profesores de los graduados de educación física, los graduados de una universidad de las escuelas federales. La metodología de investigación cualitativa es la naturaleza, carácter descriptivo. El estudio se realizó con 13 maestros principiantes ( 9 hombres y 4 mujeres) y uso que se hace de dos técnicas de recolección de datos: entrevista y análisis de casos de enseñanza. Los datos de la encuesta muestran que la pertenencia a un campo particular del asunto es un elemento importante a tener en cuenta para el análisis de los procesos de integración profesional y maestro de aprendizaje, ya que establecen formas específicas y cruciales para convertirse en un maestro y para entrar en la profesión.

Palabras clave: Formación del profesorado. Introducción a la enseñanza. El aprendizaje del profesor. Educación física.

\footnotetext{
* Doutor em Educação, professor da Escola de Educação Física, Fisioterapia e Terapia Ocupacional da UFMG.E-mail: <angelogariglio@hotmail.com>.
} 


\section{INTRODUÇÃO}

Nas últimas décadas, o tema relativo aos processos de inserção profissional de professores iniciantes tem sido objeto de preocupação de autoridades políticas vinculadas ao campo da educação, bem como de investigadores no âmbito das universidades. Tal preocupação se justifica porque há muito as pesquisas têm constatado que os primeiros anos de inserção na carreira docente são críticos, seja pelos altos índices de abandono da profissão, seja pelas dificuldades encontradas pelos professores iniciantes de crescerem, desenvolverem-se e aprenderem as artes da profissão.

A problemática da iniciação à docência tem sido analisada sob diferentes ângulos, notadamente: desenvolvimento da identidade profissional (ENDO; REECEMILLER; SANTAVICCA, 2010, 2012; RUS; TOMSA; REBEGA; APOSTOL, 2013); caracterização da fase de indução (DALGARNO; COLGAN, 2007; VONK, 1993); problemas relativos à retenção de professores novatos (COCHRAN-SMITH et al., 2012; INGERSOLL \& ROSSI, n. d.); apreciação da formação inicial em relação à experiência da inserção profissional (HONG, 2010; MOULDING; STEWART; DUNMEYER, 2014); programas de acompanhamento de retenção de professores iniciantes (VONK, 1993); aprendizagem docente (COCHRAN-SMITH, 2012A; ROTS et al., 2012).

Neste artigo, trata-se da temática relativa aos processos de aprendizagem docente de professores de Educação Física (EF) iniciantes. Particularmente, pretende-se relacionar a aprendizagem docente, a iniciação à docência e o caráter situado da ação docente de professores de Educação Física, dada a vinculação desses a um determinado campo disciplinar peculiar.

Uma primeira discussão importante a ser feita dentro da tríade tomada como pressuposto orientador das análises que se vai realizar diz respeito aos aspectos peculiares da fase denominada de "indução". Esta, entendida como uma fase única na vida de um professor, transporta duas ideias que estão relacionadas. A primeira ressalta o caráter especial do encontro inicial com o mundo "real" (em oposição à experiência como estudante na formação inicial) de ensino. E a segunda destaca a posição central da fase de indução num contínuo mais amplo de preparação e desenvolvimento de professores. Nessa linha, a indução seria compreendida como uma arena complexa e variada de experiências singulares com a atividade educativa, isto é, uma fase de aprendizagem para ensinar, um processo de enculturação e um programa formal e informal de apoio, desenvolvimento e avaliação de professores iniciantes (BIRKELAND; FEIMAN-NEMSER; 2012; SHARON FEIMAN-NEMSER; SCHWILLE; CARVER; YUSKO, 1999; MARCELO GARCÍA, 1992).
Parte importante de debate teórico sobre o período relativo à inserção profissional tem insistido na ideia de que esse tempo deveria ser tomado como singular na trajetória de tornar-se professor. A indução não seria vista, dessa forma, como um salto no vazio entre a formação inicial e o desenvolvimento profissional. ${ }^{1}$ Ao contrário, essa fase tem, ao mesmo tempo, caráter distintivo e determinante ao alcance da maturidade profissional. Nessa perspectiva, o que ocorre com os novatos no tempo específico, no período da indução, pode ter repercussão tanto positiva como negativa, que impactará o restante de sua trajetória profissional, influenciando na sua decisão de ficar ou não na profissão e definindo que tipo de professor haverão de tornar-se (FANTILLI; MCDOUGALL, 2009). A inserção profissional seria, assim, parte de um contínuo processo de aperfeiçoamento dos professores, de transição de um professor em formação até chegar a ser um profissional mais autônomo e com maior capacidade de autorregulação (VONK, 1993).

Nessa perspectiva, os estudos têm ratificado a ideia de que o período de indução caracteriza-se por ser um momento crítico e intenso no processo de aprendizagem docente. Tal descrição explica-se basicamente por duas razões: a primeira tem relação com o fato de que os professores iniciam a profissão de forma muito solitária e sem o suporte de outros profissionais mais experientes que os ajudem no enfrentamento de uma realidade a qual desconhecem. A segunda razão está relacionada com as exigências profissionais que recaem sobre os professores novatos, que em nada se diferem das dos professores experientes, $\mathrm{e}$ para as quais esses professores não estão suficientemente preparados para lidar. Mesmo assim, deles esperam-se respostas ágeis e satisfatórias ante os desafios impostos por uma realidade tão complexa como que desconhecida.

Apesar de prevalecer ainda a percepção equivocada de que a aprendizagem docente está diretamente relacionada à formação inicial, muitas pesquisas têm apontado que o desenvolvimento profissional dos professores está fortemente ligado às experiências que estes terão nas escolas quando assumirem a responsabilidade de conduzir suas ações de ensino. Assim, o seu processo de desenvolvimento profissional tem sido visto mais como uma experiência de aprendizagem contínua e diversa (forma e informal), contrariamente aos modelos mais tradicionais de formação nos quais professores-estudantes, reunidos em auditórios, são "equipados" com teorias e métodos para, em seguida, serem enviados para ensinar na "prática". Nessa medida, tem ganhado espaço a perspectiva de que a formação continuada de professores é um processo ininterrupto de desenvolvimento pessoal e profissional.

\footnotetext{
1 A aprendizagem profissional contínua incluiria assim três fases distintas e interdependentes: a formação inicial, o período de indução e o desenvolvimento profissional (FEIMAN-NEMSER, 1983).
} 
Contrariamente à perspectiva que entende a formação como aquela que ocorre somente em momentos isolados, o processo de aprendizagem docente tem sido visto como uma experiência contínua e interminável. Sabe-se, agora, que aprender a ensinar trata-se mais dos levantamentos de questões advindas da experiência profissional, por meio de ações de reflexão individuais e coletivas dos professores, do que do recebimento de técnicas de ensino de peritos externos (COCHRAN-SMITH, 2012b).

Segundo Feiman (1983), os professores principiantes têm duas tarefas simultâneas a cumprir quando adentram os sistemas de ensino: devem ensinar e aprender a ensinar. Independentemente da qualidade do programa de formação inicial que cursaram, há alguns aprendizados sobre a profissão que somente são assimilados na prática e que repercutem sobre a própria experiência de inserção profissional, seja ela de sobrevivência e descobrimento, seja ela de adaptação e aprendizagem. As principais tarefas com que se defrontam os professores principiantes nesse processo de aprendizagem docente, no período de indução, são: adquirir conhecimentos sobre estudantes, currículo e contexto escolar; desenvolver ações de ensino que sejam significativas; manter a disciplina na sala de aula; criar um ambiente e uma comunidade de aprendizagem na sala de aula, ou seja, construir um repertório docente que lhes permita sobreviver a esse "desenvolver-se como professor" (MARCELO, 2011).

A discussão relativa à aprendizagem docente é tratada também sob a perspectiva da diferença entre professores principiantes e professores experientes. Estudos têm tentado mostrar que a experiência profissional, em muitos casos, possibilitaria aos docentes um conjunto de conhecimentos práticos ${ }^{2}$ que os ajudaria a solucionar dilemas e desafios que a profissão os impõe cotidianamente, nas escolas, de forma mais autorregulada. O que parece tão fácil ao professor experiente e, contrariamente, tão complexo ao professor novato é o resultado de inúmeras horas de contato ${ }^{3}$ e experiências de primeira mão com o

\footnotetext{
2 Ao designar o termo "conhecimento prático", está se valendo das reflexões de Schon (2000) acerca do que ele define como "talento artístico": aos tipos de competência que os profissionais demonstram em certas situações da prática que são únicas, incertas e conflituosas. Nesse processo, diferentes níveis e formas de refletir fazem-se presentes: reflexão para a ação, conhecimento na ação, reflexão na ação e reflexão sobre a ação.

3 Parece importante fazer uma ressalva sobre o caráter sempre positivo da experiência prática na escola e seu impacto no processo de desenvolvimento profissional dos professores. Existe uma crença socialmente compartilhada de que a experiência, a prática de ensinar ou o contato com a realidade são atributos que verdadeiramente contribuem para aprender a ensinar. Zeichner (1980) utiliza a palavra "mito" para referir-se às crenças segundo as quais as experiências práticas nas escolas contribuem necessariamente para formar melhores professores. Assume-se que a prática é melhor que nenhuma e que, quanto mais tempo se dedica às experiências práticas, melhor será. Ainda sobre esse ponto, Dewey (2001) vai afirmar que nem todas as experiências promovem amadurecimento dos sujeitos ou possibilitam atitudes de autocontrole. Não é suficiente insistir na necessidade da experiência, nem mesmo de atividade em experiência. Tudo depende da qualidade das experiências que se tem.
}

universo do trabalho e de experiências de reflexão sobre este (SMITH, 2005).

Estudos nessa linha de investigação mostram que os professores iniciantes estariam mais vulneráveis ao peso da complexidade e das exigências da vida escolar comparativamente àqueles mais experientes. Para estes, o domínio da sala de aula é algo mais familiar, pois têm um repertório de estados de conhecimento (contato visual, proximidade com os estudantes, habilidade para lidar com pessoas em grupo, comportamento calmante, baixo nível de voz) que lhes permite desenvolver um caminho eficiente nesse espaço de ensino. Além disso, o professor experiente tem maior capacidade de antecipar e solucionar situações-problema por meio da utilização da memória de longa duração, alcançando objetivos de maneira menos exigente; isso pode até parecer algo fácil aos olhos de um professor iniciante (BEIJAARD; VERLOOP, 1996).

Nessa etapa do processo de socialização profissional, os professores iniciantes aprendem, a duras penas, alguns dos elementos centrais da profissão docente e também um conjunto de práticas vinculadas às tradições de uma comunidade de profissionais que exercem influência sobre o mundo no qual habitam. Aprendem suas convenções, seus limites, suas linguagens e seus sistemas apreciativos, seu repertório de modelos e seu conhecimento sistemático apreciativo (SCHON, 2000). Mais especificamente, a socialização profissional dos professores seria o processo mediante o qual adquirem o conhecimento e as destrezas sociais necessárias para assumir um papel na organização escolar (VAN MAANEN; SHEIN, 1979). Durante a fase da indução, criam-se ou não condições que fazem com que esses novos membros internalizem as normas da profissão até que o principal meio de controle social seja o autocontrole (FRIESEN e BESLEY, 2013).

$\mathrm{O}$ processo de aprendizagem com as primeiras experiências de ensino impacta a compreensão que os novos professores têm do ensino e de sua identidade como docentes, e a maneira como eles se comportam profissionalmente. Um componente importante do processo de aprender a se tornar um professor é o desenvolvimento da identidade profissional docente. Nesse entendimento, a aprendizagem docente seria mais do que o saber como ensinar e/ou ser alguém que ensina. Aprender a ser professor estaria relacionado a uma visão mais ampla da função docente, ou seja, ao aprender a pensar como um professor, ao aprender a se conhecer como um professor, ao aprender a sentir como um professor e ao aprender a agir como um professor (FEIMAN-NEMSER, 2008).

Desenvolver a identidade do professor é fator importante do processo da aprendizagem docente. Isso 
porque aprender faz sentido à história do sujeito, às suas expectativas, às suas referências, à sua concepção de vida, às relações com os outros, à imagem que tem de si e à imagem que quer dar de si aos outros (CHARLOT, 2003). É uma autoconstrução profissional que evolui ao longo da carreira, sendo influenciada pela escola, pelas reformas e contextos políticos, pelo compromisso pessoal dos professores, pela vontade de aprender a ensinar, pelas crenças, pelos valores, pelo conhecimento do material ensinado, pela experiência passada e pela vulnerabilidade profissional (AKKERMAN e MEIJER, 2011).

Essa relação estreita entre identidade profissional docente e aprendizagem docente remete ao caráter situado da aprendizagem docente. Isso porque professores ensinam conteúdos particulares para estudantes singulares e em contextos particulares. Consequentemente, algumas das mais importantes aprendizagens profissionais são precisamente locais. Sobre esse ponto, vale citar algumas reflexões produzidas por Sharon Feiman-Nemser e Floden (1984), quando apontam a necessidade de se olhar a profissão docente como um campo de atuação em que se edificam múltiplas e diversas culturas docentes. Em uma revisão densa da produção teórica no campo da formação de professores, os autores criticam a crença reconfortante da existência de uma cultura docente comum. Para eles, a suposição da existência de uma uniformidade cultural na docência é insustentável. Eles defendem a tese de que, no campo de atuação profissional, convivem não apenas uma, mas várias culturas docentes. Isso porque os professores se diferem em idade, experiência, origem social, bagagem cultural, gênero, nível de ensino onde atuam, tipo de escola onde são lotados e pertencimento a um campo disciplinar específico.

Nesses diferentes contextos nos quais a profissão docente se desenvolve, forjar-se-iam culturas docentes diversas mediante o contato dos docentes com diferentes normas e interações sociais provenientes dos distintos contextos de atuação profissional e da produção diversa de recompensas intrínsecas e extrínsecas associadas ao exercício do métier profissional. Segundo esses autores, as normas e as interações conformam estilos peculiares de como os docentes percebem seu trabalho, como veem sua relação com os alunos, com outros professores, com os administradores da escola, com os pais.

O cumprimento dessas normas e as interações estabelecidas teriam variações entre os diferentes grupos de professores. Sobre as recompensas profissionais advindas das atividades profissionais, os autores as classificam como intrínsecas e extrínsecas. Recompensas extrínsecas são os benefícios públicos, como salários dignos, horas de trabalho, status elevado e poder. Recompensas intrínsecas são as recompensas psíquicas, subjetivas, aspectos do trabalho valorizados e visíveis aos olhos dos professores. Tais recompensas intrínsecas seriam a constatação por parte dos docentes de que seus alunos estão aprendendo e de que há ligação emocional estabelecida com os estudantes, interação com os colegas, satisfação em realizar um serviço valioso e gozo em desenvolver atividades de ensino. Ao desenvolver essa discussão, os autores denominam "cultura profissional" como um conjunto de sentimentos partilhados, de hábitos mentais, crenças profissionais e de modelos de interação com os alunos, com os colegas, com os administradores e com os parentes.

Uma quantidade significativa de estudos no campo da Educação Física escolar ratifica a análise que aponta para a necessidade de se reconhecer a existência e a constituição de culturas docentes no interior dos sistemas de formação e atuação profissional docente. Primeiro, existem pesquisas que mostram que um olhar mais atento dirigido ao cotidiano escolar vai identificar que, apesar de a Educação Física estar presente no currículo em função de uma determinação do marco legal da educação, essa disciplina apresenta no conjunto da cultura escolar um déficit crônico de legitimidade. O que faz com que os seus responsáveis e os partidários, particularmente os professores de EF, estejam envolvidos numa constante luta por reconhecimento. Essa evidência não é nenhuma novidade; entretanto, é interessante observar que isso se dá, entre outros motivos, pela desvalorização da sua especificidade.

A visão que se tem é a da Educação Física como auxiliar de outras disciplinas, uma espécie de apêndice da escola. Em observações do cotidiano escolar, podemse perceber gestores da escola e professores de outras disciplinas referindo-se ao momento da aula de EF como espaço de distração para os alunos, no qual os alunos "fugiriam" e compensariam a tensão proporcionada pelo esforço intelectual em sala de aula. Há grande dificuldade de percepção pelos agentes escolares da aula de Educação Física como um momento de aprendizado sistematizado e com objetivos de ensino próprios, com importância para o desenvolvimento humano dos alunos. A inserção atual da Educação Física na vida das escolas é, na maioria dos casos, potencialmente geradora de manifestações de desrespeitoa a essa disciplina e aos seus professores.

As pesquisas vêm mostrando que a visão (e as ações) que os demais agentes escolares têm da Educação Física, particularmente diretores e demais professores, justifica que ela seja entendida como uma "disciplina de segunda classe". A atual cultura escolar de Educação Física está fortemente permeada por essa condição. Essa desvalorização configura-se, às vezes, como forma de desrespeito nas dimensões do direito e da estima social dos professores, que os motivam à luta por reconhecimento ou então os levam a uma condição de "desinvestimento". 
O seu descrédito como disciplina escolar pode ser gerador de um movimento coletivo de resistência, mas também pode gerar desestímulo tanto pessoal quanto profissional em determinados professores. Tal realidade incide, portanto, diretamente na vida dos seus professores, uma vez que estes acabam desenvolvendo uma compreensão de si como docentes também de "segunda classe", pelo menos numa posição inferior aos professores das demais disciplinas escolares (BRACHT e FARIA, 2010).

Paralelamente a essa realidade de dificuldades no enfrentamento desse déficit crônico de legitimidade da EF no currículo escolar, outros estudos têm revelado que os professores de Educação Física se deparam com outros desafios colocados pelo caráter singular e próprio do ensino de tal componente curricular. Algumas das características dessa contextualidade pedagógica da EF foram descritas em pesquisa realizada por Gariglio (2004) com professores de uma escola profissionalizante. Os dados do seu estudo apontam que os professores de EF precisam aprender a lidar com modalidades de ordem e disciplina diferenciadas em relação à maioria das demais disciplinas escolares (ensinar mediante a presença constante de ruídos - risos, gritos, conversas -; com a intensa movimentação dos alunos e ocupação mais livre dos espaços); com a singularidade das condições ambientais da sala da aula da EF (incidência forte do sol, do frio e de espaços e limites físicos mais amplificados no que diz respeito à sala de aula tradicional); com o cuidado e atenção em relação à segurança e à integridade física em função da movimentação corporal dos alunos; com a carência quase que absoluta de material didático orientador da ação pedagógica, proporcionando, ao mesmo tempo, maior autonomia na condução do trabalho pedagógico e sensação de desamparo em face da carência de referências ordenadoras da prática pedagógica; com a necessidade de desenvolver tecnologias de comunicação/interação humana com potencial de persuasão dos alunos em razão da diluição de relações hierárquicas mais verticalizadas na relação professor/ alunos. Relações que são desestabilizadas pela percepção dos alunos a respeito do caráter "inútil" da EF na luta por uma vaga na universidade ou mesmo no mercado de trabalho.

Tomando essa discussão como referência, buscou-se acessar e compreender a percepção que professores iniciantes de Educação Física têm sobre os processos de aprendizagem profissional. Mais especificamente, pretende-se saber se a experiência nos primeiros anos da profissão favorece a edificação de aprendizagens profissionais significativas necessárias ao desenvolvimento profissional contínuo. E, caso aprendam, que aprendizagens seriam essas e qual a relação existente entre elas e o caráter situado do trabalho desses professores.

\section{Metodologia}

\section{Os sujeitos da pesquisa}

A primeira parte da pesquisa foi realizada com 13 licenciados/as formados/as (quatro homens e nove mulheres) pela Escola de Educação Física, Fisioterapia e Terapia Ocupacional da UFMG (EEFFTO), nos últimos quatro anos (do final de 2009 em diante), e que tivessem no máximo três anos de experiência com a docência em EF na escola. Na segunda parte, a investigação foi realizada com sete docentes (dois homens e cinco mulheres) dos 13 licenciados citados acima. E a opção por trabalhar com licenciados/as formados apenas em uma única instituição teve como objetivo a produção de análises que visassem a estabelecer relações mais críveis entre o currículo da formação inicial e sua repercussão perante os desafios colocados pelas situações de trabalho próprias de contexto de iniciação à docência em Educação Física na escola.

\section{Técnica de coleta de dados}

\section{Casos de ensino}

Investigadores da epistemologia da prática (SHULMAN, 1992) têm destacado a importância do conhecimento de casos de ensino na construção do pensamento e das práticas do professor. Os casos de ensino surgem como instância da prática e parecem oferecer oportunidades para exame e reflexão sobre a prática de sala de aula. Apresentam situações de ensino, descritas detalhadamente, que possibilitam aos futuros professores refletir sobre eventos ocorridos em determinado contexto. Shulman (1992) afirma:

\footnotetext{
O conhecimento de casos é um conhecimento de eventos específicos, bem documentados e bem descritos. Enquanto os casos em si mesmos são informações de eventos ou sequências de eventos, o conhecimento que representam é que os converte em casos. Os casos podem ser exemplos de aspectos concretos da prática - descrições detalhadas de como ocorreu um evento - completados com informação sobre o contexto, os pensamentos e os sentimentos (p. 58).
}

A análise e a elaboração de casos de ensino podem permitir aos futuros professores desenvolver e explicitar seu conhecimento profissional, já que possibilitam o estudo de várias temáticas relacionadas a diversas áreas de conhecimento; a revisão de concepções sobre ensino, aprendizagem, aluno, disciplina, avaliação, dificuldades de aprendizagem, etc. Ao mesmo tempo, os casos de ensino constituem-se em: "[...] importantes instrumentos de pesquisa - ao possibilitar não apenas apreender as teorias pessoais dos professores, o processo de construção de conhecimentos profissionais, o desenvolvimento do 
raciocínio pedagógico, como também compreender o pensamento do professor" (MIZUKAMI, 2000, p. 156).

Considerando o potencial dos casos de ensino como instrumentos de pesquisa capazes de "[...] possibilitar a apreensão e o desenvolvimento das teorias práticas de ensino que constituem o conhecimento profissional do professor" (MIZUKAMI, 2000, p. 140), aposta-se em tal procedimento metodológico por entender ser este um poderoso instrumento de acesso e reflexão sobre as situações práticas vividas pelos professores iniciantes como um determinado professor enfrenta o desafio de ensinar os conteúdos de sua disciplina, de que maneira ele lida com os conflitos com os alunos, de que forma ele se relaciona com as normas da cultura institucional da escola, como experimenta a convivência cotidiana com os seus pares. Os casos de ensino apresentam, portanto, “[...] um retrato de uma situação-problema enfrentada por um professor, uma variedade de abordagens possíveis que poderiam ter sido adotadas e algumas informações sobre como o problema foi resolvido" (MIZUKAMI, 2000, p. 152).

Foram feitas análises de sete textos escritos de casos de ensino, confeccionados por sete dos 13 professores que já haviam concedido uma primeira rodada de entrevistas. Tal descrição reflexiva sobre essa experiência prática levou em conta duas vertentes fundamentais: a referencial e a existencial (ZABALA, 1994). A vertente referencial descreve o objeto narrado, ou seja, as características dos alunos, os objetivos da aula, as situações da escola. Já a vertente existencial narra sobre si mesmo, o que envolve as decisões do professor, as emoções e as intenções.

\section{Entrevistas}

Foram realizadas duas entrevistas semiestruturadas, sendo uma primeira com 13 professores/as (quatro homens e nove mulheres) e uma segunda com sete docentes (dois homens e cinco mulheres). A primeira entrevista foi construída levando em consideração quatro eixos aglutinadores: a percepção sobre a iniciação à docência; as ações e estratégias pensadas e realizadas pelos professores com vistas ao enfrentamento da realidade; as aprendizagens docentes mais significativas; e a relação entre a formação inicial e a iniciação à docência. Já a segunda entrevista foi realizada com os sete docentes que enviaram os casos de ensino por escrito. Nela pretendeu-se aprofundar as análises dos textos escritos, em especial, os processos de aprendizagem docente.

\section{Sobre a análise dos dados}

Nesta parte do artigo, dedica-se mais detidamente a analisar os discursos dos professores que tratam de sua percepção acerca de suas principais aprendizagens. Segundo eles, estas foram incorporadas durante os primeiros anos de inserção profissional na escola. De todos os 13 participantes da pesquisa, foi unânime a percepção de que as experiências vividas nos meses iniciais da profissão proporcionaram aprendizagens significativas ao exercício da profissão docente. De início, são trazidos alguns extratos de falas dos professores quando são questionados sobre por que entendem que as experiências iniciais com o ensino impactam o processo de aprendizagem da profissão docente:

"É assim: a experiência que eu tinha de Educação Física escolar era de estágio e era em escola de esportes. Trabalhei em escola de esporte desde o início da graduação, desde o 1o- periodo; então, eu tinha uma experiência docente com turmas, mas não com turmas minhas de Educação Física. E encarar uma turma de Educação Física foi diferente e me trouxe bastante aprendizado no sentido de confrontar o que eu tinha aprendido na graduação, assim no jeito de lidar com os alunos, de falar com os alunos, de pensar minha prática e de conseguir realmente mudar minha prática pra adequar a turma. Assim, isso foi uma coisa que eu aprendi." (Luiz)

"É como se a ideia que eu tenho é porque, lógico, a gente aprende o tempo inteiro. Isso é um fato. Mesmo um professor que já está no fluxo da vida, mesmo aquele professor que já tem tudo estabelecido, o que ele acha que tem que ser, ele está aprendendo, mas, quando você está começando, é como se você tivesse colocado uns óculos. Que tudo aparece, antes você não via, e agora você está imerso na realidade; tudo apareceu na frente. Então, são muitas coisas, a aprendizagem fica mais latente, mas acontece; antes você não via porque você não estava lá dentro, você tinha uma visão de fora, e aí agora você está. Então, você colocou os óculos daquela realidade, ai tudo está passando. A impressão que eu tenho é essa. Você fica mais sensivel porque é uma mudança muito grande, de não estar na escola e agora você está e você é um professor. Essa ruptura, essa transformação te faz enxergar mais essas aprendizagens. Não que elas sejam mais ou menos do que outras fases." (Juliana).

"Porque a gente sai de um momento, de uma formação teórica em alguns momentos tentou ser prática, mas, que em momento nenhum conseguiu ser prática e a gente cai num outro mundo, numa outra realidade, completamente diferente e que é de duas uma, ou você enfrenta e tenta descobrir o que é e ai vai aprendendo, caindo e levantando, caindo e levantando ou você fala não, não quero, vou embora. Então, aí por isso que como eu decidi enfrentar eu acho que foi um momento, o tempo inteiro caindo e levantando, caindo e levantando, aprendendo o tempo inteiro. Assim, todos os momentos da minha aula têm alguma coisa que acontece que eu falo, poxa, não tinha pensando nisso ainda. Esses meninos... Desse jeito... Então, e esse primeiro impacto que a gente tem do mundo real, ele é muito dificil porque a gente chega naquele espaço cheio de sonhos. Ah não, eu quero, agora quero realizar tudo aquilo que eu pensei. E aí vem o balde de água fria. Calma aí que não é assim também não. Você pode sonhar, pode sonhar à vontade, mas é devagar, com o tempo..." (Bárbara) 
Os três relatos dos professores descritos acima deixam claro que a passagem para o mundo real da escola não é uma experiência fácil de lidar. Nessa situação convivem sentimentos de desilusão diante da impossibilidade de concretização de projetos pessoais e profissionais nutridos durante a formação inicial, de estranhamento ante uma realidade desconhecida, de descobertas sobre essa mesma realidade, de realinhamento e validação de conhecimentos aprendidos na universidade e da percepção mais evidente das responsabilidades do que é ser professor. É nesse cenário, aparentemente caótico, que coabitam sensações de angústia, de desânimo, de vontade de deixar a profissão, além de outras marcadas pelo desejo de permanecer na docência, de crescimento profissional, de uma atuação docente mais autoral, de integração da personalidade à cultura profissional. A necessidade premente de harmonizar essas duas experiências conflitantes parece ser uma das aprendizagens mais difíceis e desafiadoras da iniciação à docência.

Como os 13 sujeitos da pesquisa disseram que a inserção profissional foi geradora de aprendizagens significativas, pediu-se aos professores que tentassem descrever e denominar essas experiências. Todavia, antes de se entrar na discussão sobre as categorias de análise construídas no transcorrer na investigação, é importante citar que as experiências narradas pelos docentes trazem as marcas do contexto situado no qual se inseriram. Em alguns casos, foram mais dolorosas e dramáticas do que em outros. Em função disso, algumas aprendizagens surgem como significativas à continuidade do processo de desenvolvimento profissional, e outras nem tanto. Chamou a atenção a dura e difícil experiência de inserção profissional vivida por uma das professoras. Para tratar dessa situação específica, lança-se mão do caso de ensino por ela narrado.

\footnotetext{
“O ensino médio noturno. No início do ano, consegui uma vaga como professora designada em uma escola estadual noturna de Contagem. Ali havia uma particularidade: o prédio era emprestado pela prefeitura, e à noite funcionavam apenas turmas de ensino médio, regular e EJA. Pela primeira vez, após formada, eu seria a única professora responsável pelo ensino da Educação Física em uma escola, durante todo o ano. E, pela primeira vez também, eu assumiria turmas de ensino médio. Durante a primeira semana, enquanto a escola terminava a organização das matrículas e o fechamento das turmas, eu fiz um diagnóstico em todas as salas, procurando saber o que os alunos já tinham aprendido em suas aulas de Educação Física, além de futebol e queimada. Não foi surpresa nenhuma saber que poucos deles tinham visto algo diferente disso ao longo dos ensinos fundamental e médio. Logo iniciei minha preparação de aulas para o ano, buscando contemplar alguns temas variados:
}

peteca, ginástica, jogos e esportes com bola e jogos de tabuleiro. No primeiro mês, pude perceber que esse planejamento não sairia do papel. Primeiramente, isso aconteceu por falta de motivação dos alunos, que estavam acostumados a não ter aulas de Educação Física. Insisti e em algumas turmas consegui dar algumas das aulas que eu havia planejado; porém, veio outro problema: a falta de iluminação da escola. Este foi o principal problema a resolver, e o mais dificil, já que não dependia de apenas um fator. Como a escola era emprestada, a direção não tinha autonomia para mexer na fiação elétrica, muito embora eu acredite que tenha havido uma falta de vontade enorme em resolver esse problema, mas isso não vem ao caso. Fato é que, por causa desse problema, os alunos, que já eram/ estavam desmotivados, ficaram ainda mais sem vontade e interesse em participar das aulas. Durante os primeiros meses, eu me sentia frustrada por não conseguir trabalhar da forma como eu imaginava que conseguiria. E isso estava me fazendo muito mal. Me sentia deprimida e solitária com meu trabalho. Pensei em desistir e procurar outra escola, mas precisava do dinheiro, não podia ficar desempregada. Então, comecei a deixar as coisas acontecerem de qualquer jeito. Já não me preocupava com as aulas e tentava não me frustrar por causa disso. Nas turmas que era possivel dar aula, eu dava; nas outras, eu tentava não me importar com o fato de não dar aula. Comecei a perceber que a culpa não era só dos alunos e que tudo na escola precisava ser mudado, mas que eu, na condição de designada, pouco conseguiria fazer para transformar aquela realidade. Comecei a colocar na cabeça que aquilo seria temporário e logo seria chamada para ocupar minha vaga como concursada e teria a possibilidade de escolher uma escola melhor. Isso aconteceu no início de setembro e agora estou em outra escola, em outro turno, e muito mais feliz. Ainda não consegui trabalhar da forma como eu gostaria e como eu aprendi com meus professores, mas eu tenho noção de que posso ter esperanças, apesar de saber que ali haverá outros problemas me aguardando, o que é normal." (Ana Paula)

Ao ser questionada sobre os motivos que a levaram a escolher esse caso como significativo de sua experiência nos primeiros meses de profissão, ela respondeu desta forma:

\footnotetext{
"Porque foi uma situação que eu vivi que afetou a minha vida pessoal. Não foi só ali dentro da escola que estava... não era um problema que acontecia só ali na escola e ficava lá. Era algo que eu estava levando para mim. Eu me sentia triste e frustrada por não conseguir fazer o trabalho da forma como eu imaginava que eu daria conta... como eu dou conta. Também porque eu pensei em desistir de lecionar, pensei em fazer outra coisa, porque eu estava enxergando aquilo como um problema que seria grande demais pra eu conseguir resolver. Então eu acho que foi um caso que marcou
} 
muito o meu início profissional, que me fez pensar em desistir ou que me fez pensar em fazer as coisas de uma forma. Foi por isso que eu escolhi esse caso. Porque eu não conseguia trabalhar na escola, aí eu ficava achando que a culpa era minha, que eu não estava sabendo lidar com aquilo, como se eu não fosse boa o suficiente para conseguir trabalhar. Depois eu comecei a ver que não era bem por aí, mas, naquele momento que eu estava vivendo aquela situação, eu pensava muito nisso. Eu pensava: puxa vida, eu não estou conseguindo trabalhar, eu não sei trabalhar, eu não aprendi nada na faculdade. O que eu vou fazer aqui? Eu ficava muito frustrada com aquilo tudo, como se a culpa fosse minha, só minha, de não conseguir trabalhar. Acho que é isso." (Ana Paula).

O que foi relatado no caso de ensino e na entrevista oferece mais ou menos o quadro de desrespeito ao qual a EF e os seus docentes estão submetidos em muitas escolas pelo país, sobretudo em turnos noturnos. Não raro, o professor de EF converte-se em simples administrador de material didático, atividade que não exigiria, em princípio, formação superior. Outras vezes, assume uma postura de compensador do tédio dos alunos produzido nas outras disciplinas, como Matemática, Português, etc. (FENSTERSEIFER e GONZÁLEZ, 2013). Aqui, a comunidade escolar tenta persuadir o docente a abandonar qualquer tipo de intervenção pedagógica, mesmo aquela mais reducionista apontada pelos autores supracitados. Atrelado à baixa expectativa da escola em relação ao ensino da EF, manifesta-se o pouco interesse dos alunos no que concerne ao ensino dessa disciplina, tomada por estes como tempo de descanso, de lazer ou mesmo de estudo das disciplinas tidas como "sérias".

Indagada sobre as possíveis aprendizagens obtidas em meio a essa experiência "tóxica" e caótica ao processo de desenvolvimento profissional, a docente aponta duas que seriam para ela significativas:

\footnotetext{
"Eu aprendi a entender que os meus problemas não são culpa só de uma pessoa ou de um fator. Culpa que eu digo é que não é só uma coisa que determina que vai ser daquele jeito. Principalmente na escola pública, a gente precisa ter essa noção. Se eu tivesse essa noção antes, eu não teria ficado tão frustrada de pensar que a culpa era minha, que os alunos é que não gostavam... essas coisas assim. Eram várias coisas, vários fatores ali... E eu tentei. Talvez se hoje eu fosse passar por essa situação, talvez eu conseguiria de outra forma... Mas eu aprendi que eu teria que resolver esses problemas cada um no seu tempo. $\mathrm{Na}$ hora que você falou aí, eu já pensei que é mais de ordem pessoal. É o fato de não esperar muito do aluno. Eu acho que isso é uma aprendizagem que eu tive a partir de umas aulas que eu dei, que fiquei frustrada, porque eu achei que os meninos iam gostar, sei lá. Essas coisas que a gente pensa e aí não deu certo.
}

Então, assim, agora eu já vou... Vou tentar, se der certo, beleza. Se não der, eu não vou ficar triste. Eu já imaginando que pode dar certo e pode não dar certo. Acho que isso é uma aprendizagem." (Ana Paula).

A primeira aprendizagem diz respeito à percepção de que os obstáculos por ela enfrentados não decorrem única e exclusivamente da sua incapacidade de lidar com eles. São problemas relacionados a questões de ordem política e cultural que a ultrapassam e a antecedem e sobre as quais as margens de manobra (mais imediatas) são restritas, sobretudo para uma professora iniciante. Tal resignação pode, por um lado, anestesiar a capacidade de agenciar na direção da transformação, mesmo que o local e as condições de trabalho (materiais) sejam desfavoráveis ao trabalho; mas, por outro, pode ajudar a produzir uma postura de resiliência ante as dificuldades a serem enfrentadas.

Já a segunda parece mais preocupante, sob o ponto de vista da continuidade do processo de desenvolvimento profissional. Estudos têm mostrado que as baixas expectativas dos professores em relação às possibilidades de aprendizagem dos alunos e de si como docentes podem contribuir para reforçar o desejo de abandono da profissão, assim como produzir situações de desmobilização em relação ao trabalho (MARILYN COCHRAN-SMITH, 2012). ${ }^{4}$

Sobre esse ponto, vale a pena citar as considerações feitas por Dewey (2010) acerca do caráter de continuidade contido nas experiências. Em toda experiência, há algum tipo de continuidade que se vive e se perpetua nas experiências que a sucedem, já que afeta para melhor ou para pior as atitudes que contribuem para a qualidade das experiências subsequentes, estabelecendo certas preferências e aversões, tornando mais fácil ou mais difícil agir nessa ou naquela direção. Toda experiência é uma força em movimento. Seu valor só pode ser julgado com base em "para que" e "para onde" ela se mova. Portanto, a questão central de educação baseada na experiência é saber selecionar no presente o que se deve continuar a viver frutífera e criativamente nas experiências seguintes. Isso porque toda experiência se processa internamente (formação de hábitos, gostos, desejos, reflexões) e externamente (mudança nas condições objetivas pelas quais passam as experiências). Portanto, tomar como aprendizagem docente "esperar pouco dos alunos" pode

\footnotetext{
${ }^{4}$ Sobre esse ponto, Cochran-Smith (2006) aponta que muitas das pessoas que entram na atividade do ensino decidem por sair ou ficar na profissão. O compromisso com a aprendizagem e a melhoria de oportunidades de vida de seus alunos nas escolas seriam os fatores que fundamentariam essa escolha. Quando há uma organização para o processo de aprendizagem, e os professores são apoiados de maneira que podem ajudar a melhorar as aprendizagens dos estudantes, estes são muito mais propensos a permanecer na docência.
} 
trazer repercussões negativas ao ensino da EF (que em nada ajudará a transformar a realidade dramática por ela narrada).

Além disso, tal resignação pode arrefecer o desejo por investir em experiências de descoberta da profissão (aprendizagem docente) de forma a potencializar elementos do choque da realidade. Nesse caso, a experiência no período da indução pode impactar negativamente o desenvolvimento profissional futuro dessa professora.

Seguindo as análises sobre a percepção dos professores acerca das aprendizagens incorporadas, ainda no tempo da inserção profissional, parte significativa deles aponta que foi saber lidar melhor com o planejamento de ensino. Seguem abaixo dois a respeito:

"Eu acredito que o planejamento foi o principal aprendizado pra mim porque o ato de dar a aula, de estar com alunos, a turma, isso eu não tive dificuldades, porque eu já estava numa experiência ali com a escolinha de vôlei, que querendo ou não eu transformava numa aula de Educação Física; então, essa rotina mesmo da aula em si já era tranquila. Então, o relacionamento com os alunos eu não tenho dificuldade de falar, não tenho dificuldade de chamar atenção, de explicar, isso é supertranquilo. Agora, o planejamento muito diverso, com aulas e a diversidade de conteúdos da Educação Física, de temas na Educação Física, este é o principal aprendizado, porque eu tenho a sensação que eu consigo falar que eu sei dar uma aula de ginástica a partir do momento que eu monto o projeto e dou a aula de ginástica. A minha aula de ginástica, que dei na disciplina de Ginástica, não é o suficiente; então, preciso fazer o projeto, dar aula de ginástica pra falar que não consigo dar aula de ginástica. Eu não dei aula de ginástica e ainda vou dar agora na $3^{a}$ etapa; então, eu ainda não sei, eu estou estudando pra dar aula de ginástica; então, o aprendizado maior é o planejamento de conteúdos e temas diferentes da Educação Física." (Ranucy)

"Primeiro o planejamento. Um aprendizado. Eu sei que, quando eu planejo com antecedencia, eu fico mais tranquila. Isso me traz uma calma que eu estou caminhando dentro daquilo que eu acredito. Uma Educação Física escolar, não é um planejamento rígido não. Eu sei que (...) mas eu tenho um norteador. E eu acho que eu saí daqui da universidade com isso muito preso, de que a gente tem que organizar e tal, e eu acho que isso me sufocou. E eu acho que às vezes me sufoca. Sabe, ofato de que planejar com antecedência é a melhor opção. Então, quer dizer que, quando eu não planejo com muita antecedência, quer dizer que a aula vai ser péssima? Não. Não vai. Não vai. Isso foi um aprendizado. Não vai. Então, quer dizer que o fato de às vezes uma semana eu não conseguir planejar antes, e eu vou ali uma hora antes planejar, e vou organizar, quer dizer que está perdida aquela aula.
Isso foi uma das coisas que eu mais sofri. De ver que talvez uma aula planejada um tempo antes, que não fosse com tão antecedência, com tanta organização, ela poderia ser muito boa. Não estou dizendo que é o melhor, mas estou dizendo que isso me prendeu. Isso me angustiou. Tanto que eu quero esse final de semana planejar para a terceira etapa, e estou muito ansiosa para planejar, porque, como se eu não planejar, não vai dar tão certo, ou não vai estar tão boa dentro de tudo que eu acredito. Então, eu sei que é importante, eu fico mais tranquila, mas eu sei que esse peso, ao sair da universidade, me trouxe também muitas angústias." (Poliana)

O segundo achado que emerge dos dados desta pesquisa tem relação com a dificuldade encontrada pelos professores em saber organizar didaticamente o ensino da Educação Física no currículo escolar. Tal estorvo é motivado, segundo eles, pelo fato de existirem poucas referências didáticas que possam auxiliá-los nesse processo de organização curricular da EF. A maioria das escolas nas quais esses professores trabalham não apresenta orientações ou prescrições rígidas nessa direção. Os professores relatam que, na Educação Física, não há definição clara a priori de quais conteúdos serão trabalhados durante o ano, de como organizá-los no tempo escolar e num diálogo mais orgânico com o projeto escolar. Esse fato revela alto grau de autonomia dos professores de EF em relação ao tratamento dos conteúdos de ensino. Na maioria dos casos, não há, por parte dos seus pares nem do setor pedagógico da escola, cobranças rígidas de prestação de contas, avaliação ou acompanhamento do trabalho desses professores. Consequentemente, não há necessidade de esses cumprirem determinado cronograma de transmissão de conteúdos em função de datas em que os alunos deveriam ter tido acesso. Levando-se em conta o período das avaliações escolares ou outras datas determinadas pelo calendário escolar. Externamente às escolas, tal fato tem o seu correlato na medida em que se verifica que o mercado editorial de livros didáticos nesse campo (EF) é ainda muito restrito (em quantidade e pluralidade).

Assim, sem a presença do livro didático, o ato de planejar o ensino se apresenta como um dos maiores desafios para esses professores. Que conteúdos ensinar? Como organizar os conteúdos no tempo escolar? Quais os objetivos a alcançar? Qual a periodicidade para cada conteúdo? Como tratá-los segundo as diferentes fases da vida dos estudantes? Como relacioná-los com o projeto escolar?

Talvez em razão disso a experiência de aprender a planejar gere nesses professores sentimentos de insegurança e tensão em relação ao trabalho, ao mesmo tempo em que aviva as possibilidades de aprendizagens 
que são fundamentais ao exercício da docência. ${ }^{5}$ Sobre esse ponto, vale citar o que diz Durand (1996) sobre as diferenças entre as disciplinas de alto e baixo status no currículo escolar. Para o autor, aquelas tidas como "menores" (Educação Física e Educação Artística) possuem maior margem para a interpretação pessoal dos professores. Já os professores de disciplinas tidas como "maiores" (Matemática, Física, Português) disporiam de manuais, programas, que são, "ao final das contas", memórias externas que nutrem seus conteúdos em classe. Professores das disciplinas "menores", por não possuírem guias didáticos ou programas escolares prescritos, são incitados a propor conteúdos mais personalizados, segundo a confiança que eles têm na própria capacidade. ${ }^{6}$ Esse vazio de ordenamentos didáticos com o qual os professores de EF convivem ao estabelecerem contato com o contexto situado de trabalho na EF é relatado abaixo por uma das docentes:

\begin{abstract}
"Porque existe bem determinado o que a Matemática vai ensinar em cada série, o que a Matemática vai ensinar em cada etapa; já existe uma organização disso. Então, eu sinto que essa dificuldade do planejamento vem também de algo singular da Educação Física, de não ter um currículo definido. A gente tem algo norteador; são documentos que nos norteiam, mas não tem algo definido para todas as instituições, ou pra (...) Então, não tem algo tão constituído, consolidado, como na Matemática e no Português. Então, é singular da Educação Física, sim, esse aprendizado que eu estou tendo; ele tem relação com essa área de conhecimento porque isso ainda está sendo construído. E isso talvez não seja claro, não só pra mim. No meu modo de ver." (Poliana).
\end{abstract}

Agrega-se à falta de referentes curriculares balizadores para a organização do ensino da EF outro elemento não menos importante. Na maioria das escolas onde esses professores se inserem profissionalmente, não há uma história consolidada de enraizamento curricular da EF. Pode-se afirmar que essa disciplina carece de uma memória curricular. Nesse quadro, quando chegam às escolas, os docentes novatos se deparam com uma

\footnotetext{
5 O ensino por transmissão é mais simples. Os professores podem seguir o livro didático e o caderno de atividades. As rotinas da sala de aula são diretas, e os controles são mais fáceis de ser exercidos; há um sentimento de certeza e realização quando uma aula é dada; uma lista de fatos é contemplada ou um capítulo, finalizado, mesmo que resultem em pouco aprendizado por parte dos alunos (DARLING e HOMMOND, 2010).

${ }^{6}$ Alguns estudos têm mostrado que, diferentemente do que ocorre com os professores de EF, a aprendizagem escolar é altamente estruturada de fora do local onde os professores trabalham. Dada a força prescritiva das políticas educativas no geral e do mercado editorial em específico, os professores têm pouco controle sobre o conteúdo, enfoque e interatividade das unidades de ensino (SYKES, 1996) e têm com frequência um programa muito rígido e inadequado aos diferentes tempos escolares (GUSKEY, 1995).
}

realidade na qual não existem experiências acumuladas e registradas, seja em material escrito sobre o ensino da $\mathrm{EF}$, seja em relatos orais que possam ser partilhados por professores experientes que, anteriormente, acumularam trajetórias profissionais passíveis de ser replicadas aos professores novatos. Dessa forma, iniciar a profissão é quase sempre começar da estaca zero.

É interessante notar que o esforço gerado para organizar e sistematizar o ensino da EF tem repercussão na vida pessoal de alguns desses docentes. Planejar o ensino da EF pressupõe o exercício de organizar a vida para além do espaço e do tempo circunscrito ao trabalho na escola. Segue abaixo um relato de um dos professores sobre essa mobilização pessoal/profissional:

\begin{abstract}
"Cara, eu comecei a morar sozinho; ai eu era muito desorganizado assim; ai eu estou mais organizado hoje, eu uso agenda. Isso aqui, há três anos atrás, era impensável pegar uma agenda assim e diariamente eu escrever nela assim... Era impensável. A prática pedagógica está me exigindo uma organização extrema. Então, assim, a minha casa está mais arrumada, às vezes eu vejo um copo sujo vou lá e coloco. Eu estou mais organizado. Eu acho que isso é a aula mesmo. É o dia a dia. Se eu não for assim, eu sou engolido. Acaba que eu sempre tento, eu me sinto como se fosse um camarada assim segurando o pau da barraca, e todo mundo querendo derrubar ele, e você assim." (André).
\end{abstract}

O relato desse professor remonta às afirmações feitas anteriormente acerca do conceito mais alargado de aprendizagem docente. Aprender a ser professor não se restringe a aprender a ensinar, mas sobretudo a aprender a agir e a pensar como professor. A necessidade de conexão das experiências de organização da vida pessoal e de organização do trabalho pedagógico e viceversa remete às afirmações de Dewey (2010), quando este trata do caráter de continuidade das experiências e de sua força em movimento. Para o autor, a desconexão entre as experiências dissipa a energia, e a pessoa se dispersa formando hábitos dispersivos, desintegrados e centrífugos. Diante dessas circunstâncias, é dispensável falar de autocontrole ou de controle de experiências futuras. Isso porque a atividade inteligente envolve análise e síntese. Ela se diferencia da atividade sem propósito pelo fato de devolver a seleção de meios dentro de uma variedade de condições existentes (análise) e para seu arranjo e organização a fim de alcançar determinados objetivos e propósitos (síntese). No caso narrado pelo professor, a experiência da iniciação à docência e as demandas de organização curricular em EF exigem nova organização da vida como um todo e a necessária conexão entre essa experiência existencial e aquelas próprias da prática profissional. 
Aliados às aprendizagens vinculadas à elaboração do planejamento de ensino, os sujeitos de pesquisa apontam que um dos desafios mais críticos postos pela experiência na inserção profissional é saber como lidar com os conteúdos de ensino. Dada a inexistência de referentes claros de como organizar o ensino e de como transpô-lo para a prática, é necessário que os professores de EF reaprendam a lidar com os conteúdos, mediados agora pela necessidade de torná-los significativos aos alunos, factíveis diante da realidade concreta a qual estão imersos e compreensíveis à comunidade escolar como um todo. Seguem abaixo dois relatos de duas professoras acerca desses dilemas e desafios:

"Quando eu comecei o estágio de ginástica, eu nunca tinha sido atleta, então foi difícil ajudar as meninas a fazerem aqueles movimentos. Ensinar na escolinha como fazer os movimentos e, quando eu vejo pessoas que já tiveram experiência, até mesmo os atletas, eles têm mais facilidade de entender como aquele movimento acontece, como eu devo ajudar, auxiliar. Em relação à dança, eu tenho uma facilidade imensa porque eu danço desde criança. Então, se um aluno me pede pra explicar alguma coisa, pra fazer algum passo, eu acho necessário. Pra mim, é necessário entender qual a dificuldade daquele movimento, como ensinar, o que é mais difícil, o que é mais fácil, como ensinar aquele movimento e tal. No judô e em qualquer outro esporte, você não precisa passar por todas as práticas, mas eu acho que é um agente importante, facilitador. Por exemplo, as aulas aqui, eu aprendi muita coisa, mas me limitam até um determinado ponto. Se quiser aprofundar mais com os alunos, partir pra outros olhares... eu penso que, quando você vivencia aquela experiência, fica mais fácil. As vezes, os alunos pedem: 'Professora, o que eu faço'? 'Faz isso, faz aquilo', eu digo. Então, nas lutas, por exemplo, eu participei muito das aulas com as meninas porque o André... além de algumas não participarem das aulas porque tinham vergonha, tinham medo... eu participei pra ver como o André ensina e saber o que está acontecendo, pra entender o que fazer no dia que eu tiver de dar aquela aula, qual a melhor forma de fazer. É lógico que não quer dizer que, se eu nunca fiz luta, eu nunca vou dar aquele conteúdo. Não é por esse lado, mas facilita, sim, se você já tem experiência, fica bem mais fácil. Mas não deixa de ter de estudar sobre o conteúdo, saber a prática e não saber muita coisa daquele conteúdo. Eu acho que a aula seria outra. Eu preciso aprender um pouco mais sobre as lutas. Acho que nem é questão de justificar o conteúdo de Educação Física, mas é saber mesmo sobre como diferenciar as lutas uma da outra, as características umas das outras." (Renata).

"Porque, quando eu falo que o planejamento de conteúdos e temas muito diversos está sendo um desafio pra mim, é porque na Educação Física eu não posso só chegar, passar no quadro a matéria e pronto. Então, quando eu vou demonstrar alguma coisa, tem diferença, entendeu? Eu vou demonstrar um lançamento de dardo. É simples. Agora, demonstrar um rolamento, demonstrar uma estrela, demonstrar o saque no vôlei, são coisas simples, mas que geram em mim certo conflito. Por exemplo, eu não dei aulas de luta ainda, mas, só de pensar, eu quero dar muito a aula de lutas, mas só de pensar em eu demonstrar alguma coisa de lutas, eu começo a ficar preocupada porque eu quero dar conta, não é que eu tenho que dar conta, eu não tenho que demonstrar perfeito, mas eu quero ter essa vivência, o aluno me perguntar como é que é uma pegada, e eu saber, não vou fazer o jeito mais certo, mas eu ter essa experiência de pegar uma vez no quimono. Então, eu acho que tem essa diferença desta disciplina, sim, das outras disciplinas; essa parte prática mesmo, do nosso corpo ter que estar ali, se eu der uma aula do lado de fora da quadra só apitando. Na hora que eu vou passar a dança, fui dar Calango, nunca ouvi falar de Calango, e os meninos também, mas, e aí, eu tenho que dar conta do básico do Calango, o 'basicozinho'do Calango eu tenho que dar. Então questão de ritmo eu tenho que ter um pouquinho de ritmo mesmo, e ficar lá na frente dos meninos, pros meninos rirem de mim mesmo, e eu lá fazendo e empolgando, porque, quanto mais eu me empolgava, mais os meninos se empolgavam com aquela saia rodada, falando 'vão, gente'!, pra um lado e pro outro. Então, assim, é um pouco do nosso papel ali... A nossa vivência corporal ali junto com eles gera um desafio, acho que um desafio um pouco maior do que o de outros professores, sim." (Ranucy).

Nesses relatos, os professores ressaltam que existem duas aprendizagens centrais ao exercício de um ensino mais autônomo. A primeira delas diz respeito ao alargamento do conhecimento dos conteúdos específicos (dança, lutas), e a segunda, intimamente imbricada à primeira, aborda $\mathrm{o}$ desenvolvimento de ações didáticas voltadas ao ensino e à aprendizagem desses conteúdos aos estudantes. Esta última é denominada de "conhecimento pedagógico do conteúdo", amálgama especial de conteúdo e pedagogia que é próprio do mundo dos professores, a própria forma especial de compreensão profissional, a própria sabedoria da prática, ou seja, as máximas que guiam (ou fornecem racionalizações reflexas para) as práticas de professores (SHULMAN, 1987).

$\mathrm{Na}$ busca de construir pontes que possibilitem uma relação de maior intimidade com os conteúdos de ensino que contribuam para o desenvolvimento de ações específicas, os professores lançam-se às experimentações de variada latitude. Eles relatam a necessidade de estudos e pesquisas individuais, o desenvolvimento de experiências didáticas na presença dos alunos em sala 
de aula, a experiência da reflexão coletiva e a observação de colegas que detêm maior intimidade com determinado conteúdo. As aprendizagens que resultam dessa experiência residem no fato de que esta não é adquirida de forma mecânica ou linear, tampouco é ensinada em instituições de formação inicial. Representa, sim, uma elaboração pessoal e coletiva do professor diante do desafio de transformar em ensino os conteúdos aprendidos ou não durante sua etapa formativa (GARCÍA, 1992).

O segundo dado importante nesses relatos diz respeito à necessidade desses professores de estabelecer com determinados conteúdos da EF uma relação de maior proximidade corporal. Aqui, conhecer mais profundamente o objeto a ser ensinado exige duas relações epistêmicas diferentes com o saber a ser ensinado: a primeira trata de tentar dominar corporalmente uma atividade (algumas destrezas motoras das lutas); a segunda é saber referir-se a essa atividade como um conjunto de enunciados (normativos) que constituem um saber-objeto (o que são as lutas, sua história) (CHARLOT, 2000).

Tal ambiguidade na relação com o saber da EF reflete em parte um dos elementos constituintes da especificidade pedagógica da EF. Sobre isso, Bracht (1997) vai argumentar que os saberes transmitidos pela escola provêm, na sua maioria, de disciplinas científicas ou, então, de forma mais geral, de saberes de caráter teóricoconceitual. $\mathrm{O}$ autor entende que, diferentemente do saber conceitual, o saber de que trata a EF (e as Artes) expressa ambiguidade interna ou duplo caráter: a) ser um saber que se traduz num saber-fazer, num realizar "corporal" pedagógico; b) ser um saber sobre esse realizar corporal. Betti (1994) acrescenta à caracterização proclamada por Bracht, afirmando que a ação pedagógica a que se propõe a EF estará sempre impregnada da corporeidade do sentir e do relacionar-se.

Dada a especificidade pedagógica dos conteúdos da $\mathrm{EF}$, lidar com estes didaticamente envolve aprendizagens que vão além de seus elementos sintáticos e substantivos. ${ }^{7}$ Aprender aqui tem relação com o domínio de uma atividade, ou capacitar-se a utilizar um objeto de forma pertinente. Não é passar da não posse à posse de objeto (o saber), mas, sim, do não domínio ao domínio de uma

\footnotetext{
7 Para Schwab (1961), o conhecimento das disciplinas inclui diferentes componentes, dentre os quais o substantivo e o sintático se destacam como os mais representativos. O conhecimento substantivo se constitui com a informação das ideias e com os tópicos a conhecer, quer dizer, o corpo de conhecimentos gerais de uma matéria, os conceitos específicos, as definições, as convenções e os procedimentos. O conhecimento sintático do conteúdo completa o anterior e se expressa no domínio que tem o docente dos paradigmas de investigação em cada disciplina, do conhecimento em relação a questões tais como validez, tendências, perspectivas e investigação acumulada em seu campo de especialidade.
}

atividade. ${ }^{8}$ Este se inscreve no corpo. Aprender a lutar é aprender também a própria atividade, de maneira que o produto do aprendizado não pode ser separado da atividade. O sujeito epistêmico é, então, o sujeito encarnado em um corpo, entendendo-se, por isso, no caso, não um sistema de órgãos distintos da alma. E o corpo é um lugar de apropriação do mundo, um conjunto de significações vivenciadas, um sistema de ações em direção ao mundo, aberto às instituições reais, mas também virtuais. É também sujeito, conquanto engajado no movimento da existência, na qualidade de habitante do espaço e do tempo. Existe, assim, um Eu nessa relação epistêmica com o aprender, mas não é o Eu reflexivo que abre um universo de saberes-objetos; é um Eu imerso em dada situação; um Eu que é corpo, percepção, sistema de atos em um mundo correlato de seus atos (com possibilidades de agir, como valor de certas ações como efeito dos atos). Isso é o que o autor chama de "imbricação do Eu na situação", ou seja, o processo epistêmico em que o aprender é o domínio de uma atividade "engajada" no mundo (CHARLOT, 2000).

Assim, o domínio de certos saberes de ordem corporal constitui para os professores de EF parte importante do conhecimento pedagógico do conteúdo. Tal conhecimento se vincula com a forma como os professores ajudam os estudantes a compreender determinado conteúdo. Inclui as maneiras de representá-los e formulá-los para fazê-los compreensíveis aos estudantes (SHULMAN, 1987). A relação de intimidade corporal com os temas da EF apresenta-se como desafio à construção do conhecimento pedagógico do conteúdo.

Tal achado instiga a pensar outras formas de organização dos currículos dos programas de formação inicial e continuada que geralmente enfatizam o tratamento de saberes de ordem teórico-conceitual, em detrimento de aprendizagens construídas mediante as experiências estéticas $^{9}$ (experimentação corporal). Infelizmente, essas aprendizagens têm ocupado, cada vez mais, um lugar marginal mesmo dentro dos currículos dos cursos de formação inicial de EF, dado o predomínio do modelo da racionalidade técnica. Como bem lembra Charlot (2000), quanto mais a atividade for submetida a minivariações da situação, tanto mais estará inscrita no corpo, e maior será a dificuldade de expô-la integralmente sob a forma

\footnotetext{
8 Não se está com isso afirmando que, para ser um professor de EF, é preciso dominar as diferentes destrezas motoras provenientes dos distintos conteúdos dessa disciplina (lutas, ginástica, esportes, dança, capoeira, jogos). Isso seria impraticável dada a diversidade de práticas corporais possíveis de ser tematizadas e ensinadas nas escolas. $\mathrm{O}$ que se está dizendo é que a experiência estética com os conteúdos torna-se um elemento mediador potente ao processo de aprendizagem sobre estes.

9 A palavra "estética" vem do grego aisthesis, que significa "sensação", "sentimento". Os estudos filosóficos sobre a estética analisam o complexo dos sentimentos e das sensações e sua integração nas atividades físicas e mentais dos homens (ROSENFIELD, 2006).
} 
de enunciados. Inversamente, quanto mais atividade estiver próxima de algoritmos (sucessão de atos normatizados e sem ambiguidade), maior a possibilidade de enunciá-la.

\section{CONSIDERAÇÕES FINAIS}

Os achados centrais desta investigação confirmam o que os estudos sobre a aprendizagem docente vêm mostrando há algumas décadas, ou seja, que o processo de aprendizagem docente não cessa com a formação inicial. Relatos e percepções dos professores descritos neste artigo revelam que a experiência profissional é fonte de aprendizagens significativas, seja para fins de solidificação do desejo de permanecer na profissão, seja para fins de continuidade do desenvolvimento profissional na carreira.

Esses dados revelam que as aprendizagens incorporadas no período de indução não apenas complementam, mas aprofundam os conhecimentos obtidos na formação inicial. Tais aprendizagens trazem consigo características próprias da experiência no período da indução. Os professores expressam em seus discursos um conjunto de aprendizagens incorporadas mediante o contato inicial com o ofício docente: o desenvolvimento da capacidade de manter o equilíbrio emocional necessário ante os conflitos provenientes da relação com os alunos; as aprendizagens relacionadas ao ensino de conteúdos não tratados no currículo da formação inicial; as aprendizagens relacionadas ao planejamento de ensino e as relacionadas à organização da vida pessoal e a conexão desta com a experiência profissional.

A pesquisa ainda aponta que boa parte dessas aprendizagens mostrou-se fortemente ancorada ao contexto situado de trabalho dos professores. De um lado, estes descobrem muito rapidamente as agruras de ter de lecionar uma disciplina que sofre com um déficit crônico de legitimidade acadêmica e pedagógica. Tal contexto dificulta os processos de construção de uma identidade profissional docente mais positiva, o que cria dificuldades extras ao processo de aprendizagem profissional. Em razão dos conflitos e tensões gerados na relação com os alunos, com os pares e com os pais, sobretudo pelas baixas expectativas que a comunidade escolar tem no que concerne ao ensino da $\mathrm{EF}$, parte da energia e atenção que deveria ser canalizada para a reflexão sobre o ensino e aprendizagem dos alunos é desviada para lutas por reconhecimento e valorização profissional.

Simultaneamente, parte do estranhamento dos professores ante sua realidade de trabalho específica parece ter relação com o fato de terem de ensinar uma matéria diferente daquelas que representam o modelo hegemônico de disciplina escolar ou de uma forma escolar $^{10}$ dominante. Modelo com o qual convivem durante anos, seja na educação básica, seja na educação superior. A entrada na profissão para esses professores envolve, ao mesmo tempo, a aprendizagem de novos conhecimentos, reflexões e práticas e o exercício de desaprender um conjunto de ideias e crenças que muitas vezes são difíceis de erradicar. A palavra "desaprender" pode significar tanto um crescimento profissional não linear, mais sofrido e lento, como uma desconstrução/ reconstrução desse processo de desenvolvimento na profissão. Tal contradição assinala não só o potencial, mas também a enorme complexidade inerente à formação continuada dos educadores (COCHRAN-SMITH, 2003).

Os professores ressaltam as dificuldades de aprender a lidar com uma disciplina para a qual não há livro didático ou outros referentes curriculares. Não existem elementos de estudo que orientem de forma mais concreta e objetiva a elaboração do planejamento de ensino e o desenvolvimento de relações epistêmicas com conteúdos não tratados e/ou tratados de forma inadequada na formação inicial com os quais se busca construir uma relação de maior intimidade.

Tais aprendizagens são incorporadas via experiência prática na sala de aula; via exercício de observação de colegas de trabalho; via interação com os alunos; via conversas informais com professores mais experientes. E também por meio de pesquisa individual e de experimentação corporal que possibilitam conhecer mais profundamente conteúdos com os quais os professores têm pouca intimidade (inclusive corporal).

Essas dimensões situadas de trabalho dos professores de EF, ao mesmo tempo em que criam uma série de dilemas, dificuldades e limites ao processo de construção de identidade profissional docente positiva, são geradoras de um campo propício à experimentação e à intensificação do processo de aprendizagem docente. A necessidade de sobrevivência em um contexto profissional duplamente desigual e, em contrapartida, de maior autonomia pedagógica propicia e exige uma relação mais intensa com a profissão. O que pode contribuir para criar condições favoráveis de sobrevivência na carreira e de incorporação de aprendizagens que favoreçam a continuidade do desenvolvimento profissional.

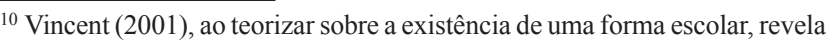
que a escola e a pedagogização das relações sociais de aprendizagem estão ligadas à constituição de saberes escriturais formalizados, saberes objetivados, delimitados, codificados, concernentes tanto ao que é ensinado quanto à maneira de ensinar, tanto às práticas dos alunos quanto à prática dos mestres. A pedagogia (no sentido restrito da palavra) se articula a um modelo explícito, objetivado e fixo do saber a transmitir. Historicamente, a pedagogização, ou seja, a escolarização das relações sociais de aprendizagem, é indissociável de uma escrituralizaçãocodificação de saberes e práticas. O modelo de socialização escolar é, portanto, indissociável da natureza escritural dos saberes a transmitir.
} 


\section{REFERÊNCIAS}

AKKERMAN, S. F.; MEIJER, P. C. A dialogical approach to conceptualizing teacher identity. Teaching and Teacher Education, v. 27 , n. 2, p. 308-319, 2011. https:/doi.org/ 10.1016/j.tate.2010.08.013

BERLINER, D. C. A personal response to those who bash teacher education. Journal of Teacher Education, v. 51, n. 5, p. 358-371, 2000. https:/doi.org/10.1177/0022487100051005004

BIRKELAND, S.; FEIMAN-NEMSER, S. Helping school leaders help new teachers: a tool for transforming school-based induction. The New Educator, v. 8, p. 109-138, Feb. 2015.

BOLIVAR, A. La identidade professional del professorado de secundária: crisis y reconstruccion. M'laga: Aljibe, 2005. $260 \mathrm{p}$.

BRACHT, V.; FARIA, B. A. A cultura escolar e o ensino da Educação Física: reflexões a partir da teoria de do reconhecimento de Axel Honneth. In: SANTOS, Lucíola L. C. P. S. et. al. Convergências e tensões no campo da formação e do trabalho docente. Belo Horizonte: Autêntica, 2010.

BRACHT, Valter. Educação Física: conhecimento e especificidade. In: SOUZA, Eustáquia S.; VAGO, Tarcísio M. Trilhas e partilhas: Educação Física na cultura escolar e nas práticas sociais. Belo Horizonte: Cultura, 1997. 388 p.

CHARLOT, B. Da relação com o saber: elementos para uma teoria. Porto Alegre: Ed. Penso, 2000.

COCHRAN-SMITH, M. A tale of two teachers: learning to teach over time. Kappa Delta Pi Record, v. 48, p. 108-122, Feb. 2015.

COCHRAN-SMITH, M. Learning and unlearning: the education of teacher educators. Teaching and Teacher Education, v. 19, p. 5-28, May 2003.

COCHRAN-SMITH, M. Why people teach and why they stay. Bank Street College of Education. Occasional Paper Series, v. 16, p. 23, 2006.

DALGARNO, N.; COLGAN, L. Supporting novice elementary mathematics teachers' induction in professional communities and providing innovative forms of pedagogical content knowledge development through information and communication technology. Teaching and Teacher Education, v. 23, p. 1051-1065, 2007. https:/doi.org/10.1016/j.tate.2006.04.037

DARLING-HAMMOND, L. EI derecho de aprender. Crear buenas escuelas para todos. Ariel. Barcelona, 2001. 464 p.

FARIA, B. A.; BRACHT, V.; MACHADO, T. S.; ALMEIDA, U. R; MACHADO, F. X. Inovação pedagógica na Educação Física: o que aprender com práticas bem-sucedidas? In: XVI Congresso Brasileiro de Ciências do Esporte/III Congresso Internacional de Ciências do Esporte, 2009, Salvador. Formação em Educação Física e Ciências do Esporte: políticas e cotidiano, 2009. Disponível em: <http://cbce.tempsite.ws/ congressos/index.php/CONBRACE/XVI/schedConf/presentat ions? searchField $=\&$ searchMatch $=\&$ search $=\&$ track $=22>$.

DARLING-HAMMOND, Linda. Experiência e educação: implicações para o ensino e a educação atuais. Petrópolis, RJ: Vozes, 2010. 145 p. (Coleção Textos Fundantes de Educação).

DEWEY, John. Experiência e educação. Petrópolis, RJ: Vozes, 2010, $165 \mathrm{p}$.
ENDO, H.; REECE-MILLER, P. C.; SANTAVICCA, N. Surviving in the trenches: a narrative inquiry into queer teachers' experiences and identity. Teaching and Teacher Education, v. 26 , n. 4, p. 1023-1030, 2010. https:/doi.org/10.1016/j. tate.2009.10.045

FARIA, B. A.; BRACHT, V.; MACHADO, T. S.; ALMEIDA, U. R; MACHADO, F. X. Inovação pedagógica na Educação Física: o que aprender com práticas bem-sucedidas? In: XVI Congresso Brasileiro de Ciências do Esporte/III Congresso Internacional de Ciências do Esporte, 2009, Salvador. Formação em Educação Física e Ciências do Esporte: políticas e cotidiano, 2009. Disponível em: <http://cbce.tempsite.ws/ congressos/index.php/CONBRACE/XV I/schedConf/presenta tions? searchField $=\&$ searchMatch $=\&$ search $=\&$ track $=22>$.

FEIMAN-NEMSER, S. Learning to teach. The Institute for Research on Teaching, v. 64, p. 1-40, 1983.

FEIMAN-NEMSER, S.; FLODEN, R. E. The cultures of teaching. The Institute for Research on Teaching, v. 74, p. 80, 1984 .

FEIMAN-NEMSER, S. et al. A conceptual review of literature on new teacher induction. National Partnership for Excellence and Accountability in Teaching, p. 1-48, 1999.

FRIESEN, M. D.; BESLEY, S. C. Teacher identity development in the first year of teacher education: a developmental and social psychological perspective. Teaching and Teacher Education, v. 36, p. 23-32, 2013.

GARIGLiO, J. A. A cultura docente de professores de Educação Física de uma escola profissionalizante: saberes e práticas em contexto de ações situadas, 2004, $275 \mathrm{f}$. Tese (Doutorado em Educação) - Departamento de Educação, PUC-Rio, Rio de Janeiro, 2004.

GONZÁLEZ, F. J.; FENSTERSEIFER, P. E. Educação Física e cultura escolar: critérios para identificação do abandono do trabalho docente. In: Congreso de Educación Física: Repensando la Educación Física, 2006, Córdoba. Actas .... Córdoba: Ipef, 2006. p. 734-746.

HONG, J. Y. Pre-service and beginning teachers' professional identity and its relation to dropping out of the profession. Teaching and Teacher Education, v. 26, n. 8, p. 1530-1543, 2010. https:/doi.org/10.1016/j.tate.2010.06.003

INGERSOLL, R.; ROSSI, R. Which types of schools have the highest teacher turnover? Issue Brief. American Inst. for Research, v. IB-5-95, p. 1-4 [s.d.].

KELCHTERMANS, G. \& BALLET, K. Micropolitical literacy: reconstructing a neglected dimension in teacher development. International Journal of Educational Research, v. 37, p. 755-767, 2002a. https:/doi.org/10.1016/S0883-0355(03) 00069-7

KELCHTERMANS, G.; BALLET, K. The micropolitics of teacher induction. A narrative-biographical study on teacher socialisation. Teaching and Teacher Education, v. 18 , n. 1, p. 105-120, 2002b. https:/doi.org/10.1016/S0742051X(01)00053-1

MACHADO, T. S.; BRACHT, V.; MORAES, C. A.; ALMEIDA, F. Q.; SILVA, M. A. As práticas de desinvestimento pedagógico na Educação Física escolar. In: XVI Congresso Brasileiro de Ciências do Esporte/III Congresso Internacional de Ciências do Esporte, 2009, Salvador. Formação em Educação Física e 
Ciências do Esporte: políticas e cotidiano, 2009. Disponível em: $<$ htp://cbce.tempsite.ws/congressos/index.php/CONBRACE/ $\mathrm{XVI} /$ schedConf/presentations? sea $\mathrm{rchField= \& searchMatch= \&}$ search $=\&$ track $=22>$.

MARCELO GARCÍA, C. Los comienzos en la docencia: un profesorado con buenos principios. Profesorado. Revista de Currículum y Formación de Profesorado, v. 13, 2011.

MARCELO, C. Aprender a enseñar: un estudio sobre el proceso de socialización de profesores principiantes. Madrid: Ed. Cide, 1991. p. 298.

MIZUKAMI, M. G. N. Casos de ensino e aprendizagem profissional da docência. In: ABRAMOWICZ, A.; MELLO, R. R. (orgs.). Educação: pesquisas e práticas. Campinas, SP: Papirus, 2000. p. 139-161.

MOULDING, L. R.; STEWART, P. W.; DUNMEYER, M. L. Pre-service teachers' sense of efficacy: relationship to academic ability, student teaching placement characteristics, and mentor support. Teaching and Teacher Education, v. 41, p. 60-66, 2014. https:/doi.org/10.1016/j.tate.2014.03.007

ROTS, I.; KELCHTERMANS, G.; AELTERMAN, A. Learning (not) to become a teacher: a qualitative analysis of the job entrance issue. Teaching and Teacher Education, v. 28, n. 1, p. 1-10, 2012. https:/doi.org/10.1016/j.tate.2011.08.008

RUS, C. L. et al. Teachers' professional identity: a content analysis. Procedia. Social and Behavioral Sciences, v. 78, p.315-319, 2013. https:/doi.org/10.1016/j.sbspro.2013. 04.302
SCHWAB, J. J. Education and the estructure of the disciplines. In: WEASTBURY, I.; WILKOF, N. (eds.). Science, curriculum, and liberal educacion: selected essays of Joseph L. Schwab. Chicago: University of Chicago Press, 1961. p. 229-272.

SHULMAN, L. L. Knowledge and teaching: foundations of the new reform. Harvard Educational Review, v. 57, n. 1, p. 1-22, Feb. 1987.

SHULMAN, L. S. Toward a pedagogy of cases. In: SHULMAN, J. H. (org.). Case methods in teacher education. New York: Teacher's College Press, 1992. https:/doi.org/10.17763/ haer.57.1.j463w79r56455411

SMITH, K. Teacher educators' expertise: what do novice teachers and teacher educators say? Teaching and Teacher Education, v. 21, p. 177-192, 2005. https:/doi.org/10.1016/j. tate.2004.12.008

VEENMAN, S. Perceived problems of beginning teachers. Review of Educational Research, 54(2), p. 143-178, 1984. https:/doi.org/10.3102/00346543054002143

VONK, J. Mentoring beginning teachers: development of a knowledge base for mentors. American Educational Research Association, v. 1, p. 1-26, 1993.

ZABAlZA, M. A. Diários de aula. Porto/Portugal: Porto Editora, 1994.

Submetido em 26/12/2015

Aprovado em 21/03/2016 